\title{
A Reintegration Program for Elderly Prisoners Reduces Reoffending
}

\author{
Kamigaki $\mathrm{K}^{1}$ and Yokotani $\mathrm{K}^{* 1,2}$ \\ ${ }^{1}$ Niigata Prison, Treatment Section, 381-4, yamafutatsu, konan-ku, Niigata-shi, Niigata, Japan \\ ${ }^{2}$ Niigata Seiryo University, Graduate School of Clinical Psychology, Suidocho, Chuo-ku, Niigata-shi, Niigata, Japan
}

*Corresponding author: Yokotani K, Niigata Seiryo University, Graduate School of Clinical Psychology, 1-5939, Suidocho, Chuo-ku, Niigata-shi, Niigata, 951-8121, Japan, Fax: 0081-25-267-0053, Tel: 0081-25266-0127, E-mail address: yokotani@n-seiryo.ac.jp

Citation: Kamigaki K, Yokotani K (2014) A reintegration program for elderly prisoners reduces reoffending. J Forensic sci criminol 2(4): 401. doi: 10.15744/2348-9804.2.201

Received Date: June 25, 2014 Accepted Date: July 10, 2014 Published Date: August 22, 2014

\begin{abstract}
Harsh sentences have resulted in many prisoners being elderly at the time of their release. However, the longer individuals have been incarcerated and the older they are, the more difficult it may be for them to re-enter free society. We developed a reintegration program to promote their successful adjustment to society and to prevent their reoffending, and evaluated its effectiveness. Participants were 25 older prisoners in Japan; all were homeless and more than 65 years old. Ten participants voluntarily participated in the reintegration programs, while the other 15 participants rejected participation in the programs. The programs provided a temporary residence, money, and job support in a community where they desired to live. Participants involved with the reintegration programs had not reoffended at 252 days, while $37.5 \%$ of those not involved in the programs reoffended. The two groups did not significantly differ in age, health status, educational level, and total length of sentence. Reintegration of older prisoners into society is more effective when done in the context of a prevention program and welfare support.
\end{abstract}

Keywords: Older prisoners; Reintegration program; Recidivism

Lists of abbreviations: SDM: Social Development Model

\section{Introduction}

The increase in general life expectancy and the introduction of harsh sentences have affected the growth of the aging prison population worldwide [1-4]. In the United States, the prison population over 50 years-old increased $44 \%$ between 1998 and 2009 [1]. In the United Kingdom, the prison population over 60 years-old increased $96 \%$ between 1990 and 2000, even though the total prison population increased only $42 \%$ [5].

Aging prison people in Japan explosively increased in a quarter of a century. The population in custody over 65 years-old increased 371\% between 1986 and 2012, even though the total population in custody decreased 28\% [6]. The explosive increase in the Japanese aging prison population can be explained by their high recidivism rates. In contrast to western countries, such as the United States [7,8] and Sweden [9], around half (47\%) of released prisoners over 65 years-old reoffended within one year after their release, whereas only $22 \%$ of those between 25 and 29 years-old reoffended [10].

Aging prison inmates develop more health problems and put a burden on the prison system. They frequently feel depressed because they have difficulties doing the activities of daily living in prison [11]. Their mental health problems often are not treated adequately in prison [12]. Prisons were basically designed for young people [13], so the conditions and treatments may be inappropriate and sometime adverse for older inmates [14]. Their worsened health problems increase the need for medical care and require additional financial costs [3,15]. Japanese prison annually costs 3 million yen (around 30,000 US dollars) per person, whereas supplemental security income annually costs only 1.8 million yen (around 18, 000 US dollars) per person [16]. Hence, facilitating the successful reentry of older inmates into free society, rather than their return to prison, is an urgent issue [3] in social safety and government finance.

\section{Social Development Model}

To facilitate the successful reentry of elderly prisoners into free society, we utilized the Social Development Model (SDM) [17]. According to environmental criminology $[18,19]$, the SDM utilized the concept of social bond [20] and proposed that people's antisocial networks elevate the risks of criminal behaviors whereas their pro-social network decrease the risks. Actually, elementary school children who did not have enough pro-social networks (e.g., family attachment) had a high risk of problem behaviors (e.g., damaging property) [21]. Teenagers who had delinquent peers also had a high risk of minor juvenile crime (e.g., hitting teacher) $[22]$. 
SDM also proposed that facilitation of students' pro-social network prevented their illegal behaviors and promoted their social participation through the networks. Facilitation of their collaborative relationships with teacher and parents decreased their smoking behaviors $[23,24]$. Supporting adolescent orphans to stay in their school also decreased their risk of human immunodeficiency virus and school dropout [25]. The supporting program also enhanced their school attendance rates and their aspiration to receive higher education [25]. These findings suggested that their pro-social networks decreased their illegal and risky behaviors and promoted their social participation.

\section{Temporary House with Case Management}

The SDM was mainly applied in juvenile population [24]. Hence, SDM programs for elderly prisoners need to be adjusted for their features. Their main features were physical difficulty, social isolation, and high risks of homelessness. Health status of elderly prisoners was worse than those of younger prisoners and their counterparts in free society [26]. Social network of them was also smaller than those of younger prisoners and their counterparts in free society [27]. Furthermore, elderly prisoners had a high risk of homelessness after their release [28,29]. These findings implied that they need medical, housing and social support in their life after their release [30].

To deliver medical care, housing service, and social support, previous study recommended a temporary house with case management. For example, case management for homeless people decreased homeless people's psychiatric symptoms [31] and emergency-department visits [32]. A temporary house with case management increased their stay in a stable housing, especially for those needs regular medical care, although a house without case management was not effective [33,34]. A temporary house with case management also facilitates recipients' pro-social networks. Their relationships with medical experts and care managers can be pro-social networks. Provision of commodities and information when they needed also facilitates them to bond with those who provided [25]. A house with case management could enhance and maintain their support networks as pro-social networks.

According to SDM [17], pro-social networks decrease the risk of illegal behaviors. Hence, a temporary house with care management could prevent aging prison people from reoffending. Previous studies reported a temporary house with care management for aging prison people, but did not report recidivism rates [35]. The present study examined the effects of a temporary house with case management on recidivism rates in a Japanese prison. We hypothesized that released elderly prisoners who participated in the reintegration programs would reoffend less than those who did not. We also reported their health status in Japan to compare with previous studies $[1,11,12,14]$.

\section{Methods}

\section{Research design}

This longitudinal study was conducted from 2011 April to 2013 December in a local Japanese prison. The prison housed about 600 offenders who had committed repetitive crimes and were sentenced to less than 10 years in prison. The present study was approved by the institutional review board of the prison. The review board checked procedure of the present study from ethical perspectives and contents of the present paper from security perspectives.

All the prison inmates provided their home addresses. Japanese probation staff checked three criteria. First, the address and addressee were matched. Second, the addressee was not a member of the Mafia. Third, the addressee was willing to take the person into their house. The addresses which met these three criteria were regarded as an "appropriate home". Those who did not fulfill these criteria were regarded as having no appropriate home. Having an appropriate home is a necessary condition for parole [36]. Then 25 men over the age of 65 without any appropriate home were sampled. Within about 10 months before their release, the first author, who is a psychologist in the prison, approached these men during their work and asked whether they had a personal home which they could go back to. After the author confirmed that all of them did not have any home, he informed them that they have a right to receive a temporary house, money, and job support through the social welfare system. Ten of them desired to use their right, so they participated in the following reintegration programs. The other 15 did not desire to use the social welfare system. Some of them $(n=7)$ rejected use of the welfare system because they said they could take care of themselves. Others $(n=7)$ rejected use of the welfare system because they had a home, even though they said they had no home. One rejected without giving any reason $(n=1)$. These 15 did not participate in any reintegration program.

Four of the participants participated in the following programs fully. The 6 participated in the programs partially. Partial participation was not funded by government, so several care plans for them could not be fully prepared before their release (e.g., travel allowance).

Practical Protocols: Before we conduct reintegration programs, we made collaborative networks among a prison, a probation office, and relief facilities on the prefectural level. Furthermore, staffs in these facilities hold study meetings regularly and keep in touch with each other. These collaborative and personal networks on the prefectural level were necessary to functionalize the programs [33]. The relief facilities also had their networks on the national level [37] and funded by Japanese government [38]. Their networks also enable elderly prisoners to choose from a wide range of living places. 
The programs before their release had four-steps. First, social workers in the prison met participants personally and designed reintegration plans for them. Second, the plans were reviewed by the prison staff, probation staff, and outside experts. Third, the participants' information was sent to community staffs where they desired to live. Fourth, the community staffs implemented the plans, such as preparing a temporary house, livelihood assistance, and job support before their release.

The programs after their release included two steps. First staffs conducted follow-up interview and checked their living condition and their utilization of medical and welfare care services. If they need more help, staffs in relief facilities counseled them and consulted their family and day care staffs [38].

\section{Sample Description}

The participants were 25 inmates from a Japanese prison (see Table 1 for demographic information). All were Japanese males over 65 years-old; their average age was 69.5 years-old. On average, they had been imprisoned 7.8 times, and had spent a total of 5,274 days in prison. On average, they were sentenced to 725.3 (S.D. = 514.3) days in jail for each crime. Most $(76 \%)$ of them were jailed on charges of property crimes.

\section{Constructs and Study Measures}

Data were collected from Japanese prison records and medical records. The prison records were made by prosecutors and prison staffs and included participants' age, educational levels, number of times in prison, duration between present and previous crimes, present periods of sentence, their main crime, and total periods of sentences. The medical records were made by medical doctors. A physician in the prison mainly diagnosed them according to the international classification of diseases $10^{\text {th }}$ edition [39]. When some of them were out of his domain, they were referred to general hospitals and diagnosed by specialists, such as oncologist and surgical pathologist.

Participants were also interviewed personally about their home by the first author before the 10 months and 3 days of their release. After their release, their crime records were tracked by correctional information network system in Japan. If they reoffended, the system added their reoffending data and main crime. For those who reoffended, their survival duration in free society was calculated based on the dates of their release and their arrest. For those who did not reoffend, their survival duration was calculated based on the date of their release and the date of our last review of their criminal system records.

\section{Data analysis}

To obtain estimates of the survival curve at 252 days, the Kaplan-Meyer survival method was used. The log-rank test was also used to test significant differences between the survival curves of those who did and did not participate in the reintegration programs. Cox's proportional-hazard regression models were also used to obtain crude and hazard ratios for the programs. Several hazard coefficients were not convergent, so the minimal coefficients were estimated in the range of the greatest value of log likelihood function.

\section{Results}

\section{Descriptive results}

The 20 participants (80\%) did not have a high school diploma. The 1 participant did not complete elementary school, whereas only 3 participants $(12 \%)$ received college degree. They also had multiple illness $(\mathrm{M}=2.9, \mathrm{~S} . \mathrm{D} .=2.4)$ caused by circulatory $(76 \%)$, genitourinary (40\%), respiratory (32\%), and digestive (28\%) dysfunctions (Table 1).

The two groups of participants, who did or did not participate in the reintegration programs, did not significantly differ in age, educational level, number of diseases, number of times in prison, survival duration in free society between the present and previous crimes, present length of sentence, their main crime, total length of sentences, and average length of sentence per crime (Table 1). Six of the 25 released prisoners reoffended after an average of 111 days following their release ( $\min =53$ days, $\max =155$ days). Five of the offenses were property crimes (theft 4, fraud 1), and one involved bodily harm. All of the offenses were committed by men who did not participate in the reintegration programs.

\section{Effects of reintegration programs on participants' survival in free society}

Figure 1 shows the survival duration in free society of the released elderly prisoners. The men who did not participate in reintegration programs gradually decreased their survival rates in free society, although $62.5 \%$ of them survived without reoffending for 252 days following their release. On the other hand, all of those men who participated in the reintegration programs had not reoffended in the 252 days following their release.

The log-rank test confirmed that the reintegration programs significantly affected the participants' survival curve in free society $\left(\chi^{2}\right.$ $=728.8, p<.0001)$. Cox's propositional analysis in a stepwise fashion was also used. The independent variables were participant's age, educational level, number of imprisonments, duration between present and previous crime, total length of sentences. The dependent variable was their survival duration without reoffense in free society. The analysis selected the reintegration programs as the single most significant effect on their survival curves in free society $(\beta=-22.9$, crude hazard ratio $=0.000,95 \%$ confidential 


\begin{tabular}{|c|c|c|c|c|c|c|c|c|c|}
\hline & \multicolumn{4}{|c|}{$\begin{array}{c}\text { Reintegration Programs } \\
n=10\end{array}$} & \multicolumn{4}{|c|}{$\begin{array}{c}\text { No Reintegration Program } \\
\qquad n=15\end{array}$} & \multirow[b]{2}{*}{$d$} \\
\hline & $m$ & s.d & $\max$ & $\min$ & $m$ & s.d & $\max$ & $\min$ & \\
\hline Age (years) & 71.6 & 5.2 & 81 & 65 & 68.1 & 2.9 & 76 & 65 & 0.9 \\
\hline Educational level & $3.4^{\mathrm{a}}$ & 1.0 & 6 & 1 & $3.8^{\mathrm{b}}$ & 1.1 & 6 & 3 & 0.3 \\
\hline The number of diseases & $2.9^{\mathrm{c}}$ & 1.1 & 5 & 1 & $2.9^{\mathrm{c}}$ & 3.0 & 12 & 0 & 0.0 \\
\hline Diseases of the circulatory system & $70 \%$ & & & & $80 \%$ & & & & \\
\hline Diseases of the genitourinary system & $30 \%$ & & & & $46 \%$ & & & & \\
\hline Diseases of the respiratory system & $30 \%$ & & & & $33 \%$ & & & & \\
\hline Diseases of the digestive system & $20 \%$ & & & & $33 \%$ & & & & \\
\hline $\begin{array}{c}\text { Certain infectious and parasitic } \\
\text { diseases }\end{array}$ & $20 \%$ & & & & $26 \%$ & & & & \\
\hline Number of imprisonments & 7.8 & 5.4 & 19 & 2 & 7.8 & 6.1 & 22 & 2 & 0 \\
\hline $\begin{array}{l}\text { Survival duration between present } \\
\text { and previous crime (days) }\end{array}$ & 190 & 118 & 402 & 7 & 347 & 440 & 1538 & 7 & 0.5 \\
\hline Present sentence(days) & 741 & 575.8 & 2160 & 210 & 670 & 472.6 & 1620 & 150 & 0.1 \\
\hline Property crime rate & $90 \%^{\mathrm{d}}$ & & & & $66 \%{ }^{\mathrm{e}}$ & & & & \\
\hline Total days of all sentences & 5463 & 3889.0 & 11880 & 810 & 5148 & 4535.9 & 12450 & 780 & 0.0 \\
\hline Average sentence per crime (days) & 818.5 & 749.0 & & & 619.7 & 287.5 & & & 0.4 \\
\hline Homeless rate 3 days before release & $20 \%^{\mathrm{f}}$ & & & & $40 \%^{\mathrm{g}}$ & & & & \\
\hline
\end{tabular}

a: The 1 did not complete his elementary school. The 6 completed their junior high school. The 2 dropped out of their high schools. The 1 completed his university.

b: The 8 completed their junior high school. The 3 dropped out of their high school. The 2 completed their high schools. The 2 completed their universities.

c: For example, they suffered from circulatory diseases (Hypertension $(n=10)$, sequelae of cerebral infarction $(n=2)$, pile $(n=1)$, recurrent cardiac arrest $(n=1))$, genitourinary diseases (chronic kidney disease $(n=9)$, hypertrophy of prostate gland $(n=2)$ ), respiratory diseases (bronchial asthma $(n=3)$, pleural plaque with presence of asbestos $(n=2)$, interstitial pneumonia $(n=2)$, chronic obstructive lung disease $(n=$ 1)), and digestive diseases (constipation $(n=3)$, chronic diarrhea $(n=1)$, chronic gastritis $(n=1)$, Gastro-esophageal reflux disease with esophagitis $(n=1)$, liver cysts $(n=1)$ ). The five participants were insomnia and four were chronic viral hepatitis $\mathrm{C}$. The three also had cancer (stomach cancer, neck cancer, and suspected bladder cancer).

d: They were sentenced on a charge of theft $(n=6)$, damage to property or building $(2)$, fraud $(1)$, and homicide attempts (1).

e: They were sentenced on a charge of theft $(\mathrm{n}=4)$, fraud (4), embezzlement (2), assault (1), injury (1), violation of stimulant control acts (2), and violation of road traffic acts (1).

f: 10 months before their release, they had no place to go back to. Those who had no place were regarded as homeless. They planned to go to welfare facilities $(n=4)$, retirement house $(1)$, a flat $(1)$, brother's house

(2), and no place (2). All of them utilized welfare systems. Those who had no place were instructed to go to a specific reintegration center that could help them.

g: 10 months before their release, they had no places to go back to. They planned to go to local relief facilities $(n=2)$, brother's house (1), nephew's house (1), daughter's house (1), wife's house (1), friend's house (1), own house (2), and no place (6).

Table 1: Characteristics of participants

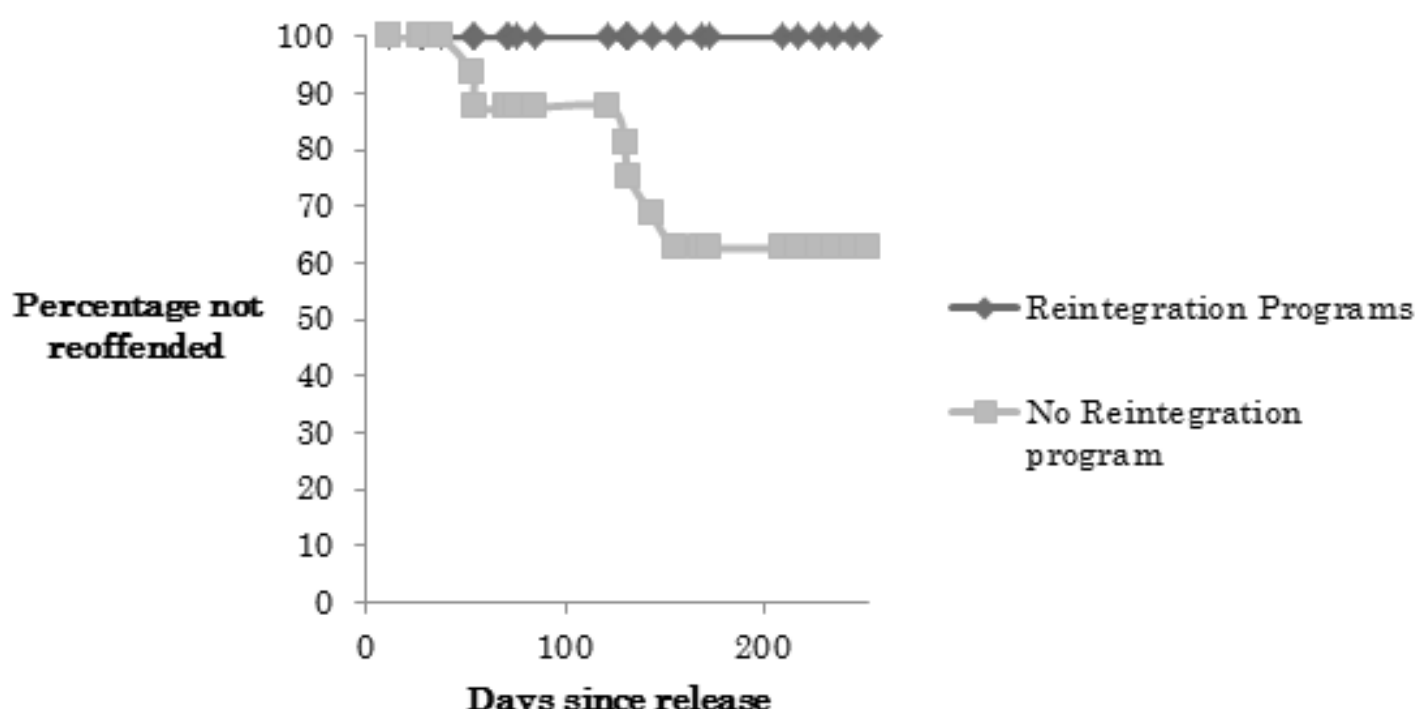

Figure 1: Comparison of survival duration in free society between aging prison people with and without reintegration programs 
interval is $(0.000-0.000), p<0.001)$. There was an age difference between the men who did or did not participate in the reintegration programs, but it did not reach significance $(t=1.8, d f=13, p=0.8)$. We obtained an adjusted hazard ratio of reintegration programs with age. The adjusted hazard ratio was significant $(\beta=-31.0$, adjusted hazard ratio $=0.000,95 \%$ confidential interval is $(0.000-0.000), p<0.001$ ), although their age did not affect their survival curve in free society (adjusted hazard ratio $=0.88,95 \%$ confidential interval is $(0.559-1.392), p=0.28)$.

\section{Discussion}

Our study found that elderly prisoners experienced poorer health than their counterparts in Japan. In line with previous studies [26], comparison of their health status with general Japanese clients over 65 [40] implied that they had high risks of diseases of circulatory (76\% V.S. 23\%), genitourinary (40\% V.S. 4\%), respiratory (32\% V.S. $8 \%$ ), and digestive systems (28\% V.S. $5 \%$ ). Many studies in western countries confirmed their poor health status $[1,11,12,14]$, but not in Asian countries. Our data supported their poor health status and clarified that elderly prisoners suffered from multiple deceases in many countries. Clarification of their status is important from a human rights perspective, because they were mostly neglected in investigations [2] in spite of their deprived environments [3,4].

We also developed reintegration programs for elderly prisoners based on SDM [20-22,24]. From SDM perspectives, our programs embedded elderly released prisoners in multiple pro-social networks through official institutions [25]. These pro-social networks prevented their illegal behaviors and promoted their social participation [23,24]. On the other hand, our findings can be interpreted from routine activity perspectives [19]. Continuous support from the day care staffs might function as regular monitoring, regardless of whether the staffs were actually intended to monitor them. Regular monitoring might decrease their criminal attempts, because they fear being exposed for their crime [18]. Hence, the day care support might improve their criminogenic environments [19]. They might not reoffend because they simply lose their opportunities to offend [18].

From the perspectives of basic human needs [41], their reoffending in free society might result from difficulties to earn their living after their release. Japanese elderly prisoners committed theft two times more than American counterparts $[1,6]$. Most of Japanese elderly prisoners repeated theft because of their difficulties to earn their living after their release [42]. Japanese high rates of theft in elderly prisoners might explain difficulties in their social life and high risks of reoffending compared to those in the United States and Europe. These data suggested that they committed crimes to earn their living. Our reintegration programs involving a temporary house and care management system, could satisfy their basic human needs, such as nutrition, medication, sanitation, and housing $[31,32,34]$. Hence, our programs might lift them out of poverty and enable them to survive in free society. Their freedom from poverty might eliminate their needs to commit crime and improve their survival duration in free society.

The present study has three limitations, limited sample, incomplete assessment and nonrandomized treatment design. First, the number of our sample $(\mathrm{N}=25)$ is too small to present conclusive evidence. Future study needs more sample. Second, our participants were not assessed by mental health professionals. Those who rejected programs might be more antisocial than those who accepted. Antisocial elderly prisoners could reject programs and reoffend crime more frequently than sociable elderly prisoners. Future study needs assessment of their mental health. Third, our participants were not randomly assigned, so those who rejected reintegration programs might be different from those who participated in the programs, even though they were no significant differences in age, educational level, health status and basic criminal records.

Furthermore, half of the participants who rejected our programs reported that they could take care of themselves. Therefore, they might value their liberated life as greater than the value of a welfare life in society. Their framework of values might be different from those who chose the welfare lifestyle, so their decision making might be different from their counterparts [43]. Their tendency to be autonomous might lead to a liberated life in free society but at the same time stimulate reoffending, because their crimes were rewarded in multiple ways [44]. Understanding their framework could be helpful to identify promotional and obstructive factors of their reoffending.

\section{Conclusion}

Our study found that reintegration programs increased the non-criminal survival duration of elderly released prisoners. Reintegration of this population into general society is a global issue $[3,5,6,10]$, so our effective reintegration programs could be a method for solving a global problem. Reintegration programs were effective for homeless prisoners over 65 years-old, so the programs should be used with this population without qualification. Qualification of the program recipients, such as being a veteran, is not productive, because elderly prisoners without qualifications have many health and financial problems like those with qualification [29]. Surely, the programs require an expense [15]. Furthermore, old age and arrest histories predicted difficulties of reintegration into free society [28]. To circumvent the prediction, however, sheltered housing with community-based support teams is the best choice in our knowledge $[31,33]$. Welfare costs might increase for elderly prisoners temporarily, but the cost will be balanced out after they live in the community and work regularly [32,35]. Furthermore, their lifestyles without deprivation are invaluable and could safeguard their human rights [13]. Introduction of continuous support at the community level is more effective to prevent their reoffending than the introduction of harsh sentences. 


\section{Acknowledgements}

We thank the prison staffs for their cooperation and assistance. We also thank Dr. Tai Kurosawa for his insightful feedback on our draft. The present study was funded by the Nikkoso Foundation for Safe Society (SZ2014A-004).

\section{References}

1. Aday RH, Krabill JJ (2013) Older and geriatric offenders: Critical issues for the 21st century. Special Needs Offenders in Correctional Institutions, SAGE Publications Inc, California: 203-32.

2. Maschi, Viola, Morgen (2013) Trauma and coping among older adults in prison: Linking empirical evidence to practice. Gerontologist. Advance online publication.

3. United Nations Office on Drug and Crime (2009) Handbook on prisoners with special needs. Vienna, Austria

4. Williams B, Abraldes R (2007) Growing older: Challenges of prison and reentry for the aging population. Public health behind bars: 56-72.

5. Howse K (2003) Growing old in prison: A scoping study on older prisoners. London: Centre for Policy on Ageing and Prison Reform Trust.

6. Research and Training Institute of the Ministry of Justice (2013) White paper on crime. Tokyo: Nikkei Insatsu (In Japanese).

7. Langan PA, Levin DJ (2002) Recidivism of prisoners released in 1994. Federal Sentencing Reporter 15: 58-65.

8. Uggen C (2000) Work as a turning point in the life course of criminals: A duration model of age, employment, and recidivism. American Sociological Review 67: 529-46.

9. Fazel S, Sjöstedt G, Långström N, Grann M (2006) Risk factors for criminal recidivism in older sexual offenders. Sex Abuse 18: 159-67.

10. Research and Training Institute of the Ministry of Justice (2007) White paper on crime.

11. Williams BA, Lindquist K, Sudore RL, Strupp HM, Willmott DJ, et al. (2006) Being old and doing time: Functional impairment and adverse experiences of geriatric female prisoners. J Am Geriatr Soc 54: 702-7.

12. Fazel S, Hope T, O’Donnell I, Jacoby R (2004) Unmet treatment needs of older prisoners: A primary care survey. Age Ageing 33: 396-8.

13. Human Rights Watch (2012) Old behind bars-Human Rights Watch.

14. Williams BA, Baillargeon JG, Lindquist K, Walter LC, Covinsky KE, et al. (2010) Medication prescribing practices for older prisoners in the Texas prison system. Am J Public Health 100: 756-61.

15. Becker GS (1974) Crime and punishment: An economic approach Essays in the Economics of Crime and Punishment, Columbia University Press, New York: $1-54$.

16. Nakajima T (2011) An Economic View of Criminal Justice (Japanese). Japanese Journal of Sociological Criminology 36: 42-61.

17. Hawkins JD, Weis JG (1985) The social development model: An integrated approach to delinquency prevention. Journal of Primary Prevention 6: $73-97$.

18. Clarke RV, Weisburd D (1994) Diffusion of crime control benefits: Observations on the reverse of displacement. Crime Prevention Studies 2: 165-84.

19. Felson M, Cohen LE (1980) Human ecology and crime: A routine activity approach. Human Ecology 8: 389-406.

20. Hirschi T (1986) On the compatibility of rational choice and social control theories of crime. The reasoning criminal: Rational choice perspectives on offending, Germany: 105-118.

21. Fleming CB, Catalano RF, Oxford ML, Harachi TW (2002) A test of generalizability of the social development model across gender and income groups with longitudinal data from the elementary school developmental period. Journal of Quantitative Criminology 18: 423-39.

22. Agnew R (1991) A longitudinal test of social control theory and delinquency. Journal of Research in Crime and Delinquency 28: 126-56.

23. O’Donnell J, Hawkins JD, Catalano RF, Abbott RD, Day LE (1995) Preventing school failure, drug use, and delinquency among low-income children: long-term intervention in elementary schools. Am J Orthopsychiatry 65: 87-100.

24. Hawkins JD, Catalano RF, Miller JY (1992) Risk and protective factors for alcohol and other drug problems in adolescence and early adulthood: implications for substance abuse prevention. Psychological bulletin 112: 64-105.

25. Hallfors D, Cho H, Rusakaniko S, Iritani B, Mapfumo J, et al. (2011) Supporting adolescent orphan girls to stay in school as HIV risk prevention: evidence from a randomized controlled trial in Zimbabwe. American journal of public health 101: 1082-8.

26. Fazel S, Hope T, O’Donnell I, Piper M, Jacoby R (2001) Health of elderly male prisoners: worse than the general population, worse than younger prisoners. Age ageing 30: 403-7.

27. Bond GD, Thompson LA, Malloy DM (2005) Lifespan differences in the social networks of prison inmates. Int J Aging Hum Dev 61; 161-78.

28. Caton CL, Dominguez B, Schanzer B, Hasin, DS, Shrout, PE, et al. (2005) Risk factors for long-term homelessness: Findings from a longitudinal study of firsttime homeless single adults. Am J Public Health 95: 1753-9.

29. Williams BA, McGuire J, Lindsay RG, Baillargeon J, Cenzer IS, et al. (2010) Coming home: Health status and homelessness risk of older pre-release prisoners. J Gen Intern Med 25: 1038-44.

30. Onishi N (2007) Elderly inmates find amenities in Japan’s prisons. New York Times. November 2.

31. Hwang SW, Tolomiczenko G, Kouyoumdjian FG, Garner RE (2005) Interventions to improve the health of the homeless: A systematic review. Am J Prev Med 29: 311-9.

32. Sadowski LS, Kee RA, VanderWeele TJ, Buchanan D (2009) Effect of a housing and case management program on emergency department visits and hospitalizations among chronically ill homeless adults: a randomized trial. JAMA 301: 1771-8.

33. Metraux S, Culhane DP (2004) Homeless shelter use and reincarceration following prison release: Assessing the risk. Journal of Criminology \& Public Policy 3: $139-160$

34. Clark C, Rich AR (2003) Outcomes of homeless adults with mental illness in a housing program and in case management only. Psychiatric services 54: 78-83.

35. Maschi T, Viola D, Sun F (2013) The high cost of the international aging prisoner crisis: Well-being as the common denominator for action. The Gerontologist 53: 543-54. 
36. Ministry of Justice (2013) Rules of social treatment for people who commit acts of crime and delinquency. (in Japanese) Retrieved March $20,2014$.

37. Japanese Association of the conference for Reintegration into civilian life (2014) Japanese Association of the conference for Reintegration into civilian life (in Japanese).

38. Ministry of Health, Labour and Welfare (2012b) Facilitation of reintegration into civilian life. (in Japanese).

39. World Health Organization (2004) International statistical classification of diseases and related health problems.

40. Ministry of Health, Labour and Welfare (2012) Patient Survey.

41. Hicks N, Streeten P (1979) Indicators of development: The search for a basic needs yardstick. World Development 7: 567-80.

42. Research and Training Institute of the Ministry of Justice (2010) White paper on crime 2010.

43. Tversky A, Kahneman D (1981) The framing of decisions and the psychology of choice. Science 211: 453-8.

44. Wood PB, Gove WR, Wilson JA, Cochran JK (1997) Nonsocial reinforcement and habitual criminal conduct: An extension of learning theory. Criminology 35: $335-66$ 